\title{
A technical modification for percutaneous tracheostomy: prospective case series study on one hundred patients
}

\author{
Joao B Rezende-Neto ${ }^{1 *}$, Argenil J Oliveira ${ }^{2}$, Mario P Neto², Fernando A Botoni ${ }^{1}$ and Sandro B Rizoli ${ }^{3}$
}

\begin{abstract}
The purpose of this study is to describe a technical modification of percutaneous tracheostomy that combines principles of the Percu Twist ${ }^{\mathrm{TM}}$ and the Griggs-Portex ${ }^{\mathbb{B}}$ methods in a reusable kit. One hundred patients underwent the procedure. There were no false passage, tube misplacement, or deaths related to the procedure. There were two minor bleedings managed conservatively. The technical modification described in this study is safe and simple to execute.
\end{abstract}

Keywords: Percutaneous tracheostomy, technique.

\section{Introduction}

Tracheostomy is one of the most frequently performed surgical procedures in intensive care unit (ICU) patients [1]. Percutaneous tracheostomy has gained widespread acceptance as an alternative to open surgical tracheostomy with the advantage of "bedside" performance and minimal morbidity [2-4]. Most percutaneous tracheostomy methods incorporate the Seldinger technique to gain initial access to the tracheal lumen. However, after that initial step, a number of variations have been described [2,4-10]. The method introduced by Ciaglia and colleagues in 1985, has become the most popular technique for percutaneous tracheostomy [2]. Different strategies to dilate the tracheal breach are utilized in the Percu Twist ${ }^{\mathrm{TM}}$ technique (Rüsch, Kernen, Germany) and in the Griggs method (Portex ${ }^{\circledR}$ Smiths Medical International Ltd., Hythe, Kent, UK) [5,10-12]. In the Percu Twist ${ }^{\mathrm{TM}}$ technique a tracheal stoma is created by a screwlike dilating device, whereas in the method introduced by Griggs a pair of forceps are used to dilate the tracheal breach [5,9-14]. Compression of the anterior tracheal wall is minimal in both methods potentially reducing injury to the posterior wall $[12,13]$.

\footnotetext{
* Correspondence: jbrezende.ufmg@gmail.com

'Universidade Federal de Minas Gerais and Risoleta Tolentino Neves Hospital, Brazil

Full list of author information is available at the end of the article
}

The aim of this study is to describe a technical modification of percutaneous tracheostomy that combines the principles of the Percu Twist ${ }^{\mathrm{TM}}$ and the Griggs-Portex ${ }^{\circledR}$ methods.

\section{Materials and methods}

This prospective case series study was approved by the Research Ethics Committee of the Universidade Federal de Minas Gerais, Belo Horizonte, Brazil (resolution number: ETIC 0392.0.203.000-10), in accordance with the WMA Declaration of Helsinki - Ethical Principles for Medical Research Involving Human Subjects. A family member responsible for the patient was contacted for informed consent prior to the procedure. Data were obtained prospectively (data collecting sheet) at the Risoleta Tolentino Neves University Hospital Trauma Center (affiliated to the Universidade Federal de Minas Gerais) from June 1, 2010 to March 31, 2011. Inclusion criteria were age 18 years or older and an indication for tracheostomy. All percutaneous tracheostomies, as well as, ultrasound and bronchoscopy were performed by the authors JBRN, AJO, MPN. General surgery residents of the Federal University of Minas Gerais performed the procedure under supervision. Data included demographics, indication for tracheostomy, body mass index (BMI), thyromental distance (measured from the thyroid notch to the inferior border of the mentum), tracheostomy tube size (internal diameter), and acute 
complications. Procedure time was recorded by a nurse with a digital stopwatch. It is our practice to correct the coagulation parameters of the patients prior to percutaneous tracheostomy. Therefore, we also reviewed the data pertaining to prothrombin time, activated partial prothrombin time, platelet count, and the international normalized ratio (INR).

\section{Modified Percutaneous Tracheostomy Technique}

The instruments used for percutaneous tracheostomy in this work were manufactured from stainless steel and are reusable (Figure 1). All mechanically ventilated patients are sedated (midazolan 1-2 mg and fentanyl 100-200 mcg), paralyzed (pancuronium 0.04-0.1 mg/Kg), and placed on $100 \%$ oxygen starting 5 minutes before and until 5 minutes after the completion of the procedure. Positive end expiratory pressure (PEEP) setting is not changed for the procedure. A pulse oximeter (Datex-Ohmeda Inc., Tewksbury, MA) is used to assess hemoglobin oxygen saturation. Trauma patients with cervical spine cleared by physical examination in addition to radiograph of the neck and/or computed tomography scan, have their neck slightly extended by a 10 $\mathrm{cm}$ high pillow placed underneath the shoulders. Otherwise, the patient's neck and the bed are maintained in neutral position. If the cervical collar has to be removed a head immobilization device is used to stabilize the cervical spine (HeadBed ${ }^{\mathrm{TM}}$ II, Laerdal do Brasil, Barueri, SP, Brazil).

The operative site is prepared with $10 \%$ povidone iodine solution and infiltrated with $2 \%$ lidocaine (Astra Zeneca, Sao Paulo, Brazil);10 mg/Kg maximum dose. Ultrasound of the neck is performed with an $8 \mathrm{MHz}$ Ultrasound Vascular Probe (Toshiba Nemio XG,

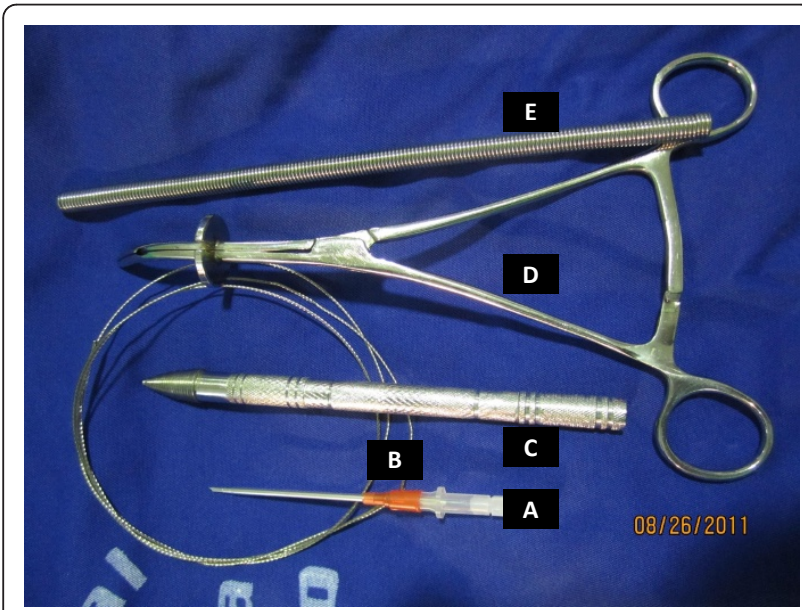

Figure 1 The instruments used for percutaneous tracheostomy (A) The $14 \mathrm{G}$ intravenous catheter- Jelco ${ }^{\mathbb{B}}$; (B) the guidewire; (C) the threaded tip dilator; (D) the self retaining retractor; $(E)$ the spherical tip flexible introducer.
Toshiba America Medical Systems, Inc. Tustin, CA) to assess vascular anatomy of the anterior neck, the distance between the skin and the trachea in the midline, as well as, to identify the thyroid isthmus, the cricoid cartilage, and $1^{\text {st }}$ to $3^{\text {rd }}$ tracheal rings (Figure 2 ). The endotracheal tube is pulled back under ultrasound guidance until the cuff is at the level of the thyroid cartilage, thus avoiding puncture of the cuff. The cricoid cartilage is palpated, and a $1.5 \mathrm{~cm}$ vertical incision is made immediately below that point. The subcutaneous tissue is bluntly dissected with hemostats until the pretracheal fascia is exposed. The trachea is punctured between the first and second, or the second and the third tracheal rings with a $14 \mathrm{G}$ intravenous catheter needle (Jelco ${ }^{\circledR}$; Medex, Carlsbad, CA) attached to a fluid filled $10 \mathrm{cc}$ syringe, under ultrasound guidance. As soon as aspiration of air into the syringe is confirmed, the intravenous catheter is advanced into the trachea and the needle is removed. A flexible guidewire is gently passed through the intravenous catheter into the trachea; the catheter is removed afterwards (Figure 3). Ultrasound is once again used to verify endotracheal positioning of the guidewire. A threaded dilator $(6 \mathrm{~mm}$ internal diameter) is advanced into the trachea, over the guidewire, for approximately $1 \mathrm{~cm}$ by clockwise rotation; minimal pressure is exerted on the anterior tracheal wall (Figure 4). The threaded dilator is removed by counter clockwise rotation after air escape through the lumen is detected. A self-retaining retractor forceps, with a limiter ridge, is passed over the guidewire into the trachea in locked position. The retractor is opened to enlarge the tracheal breach laterally, and to maintain the

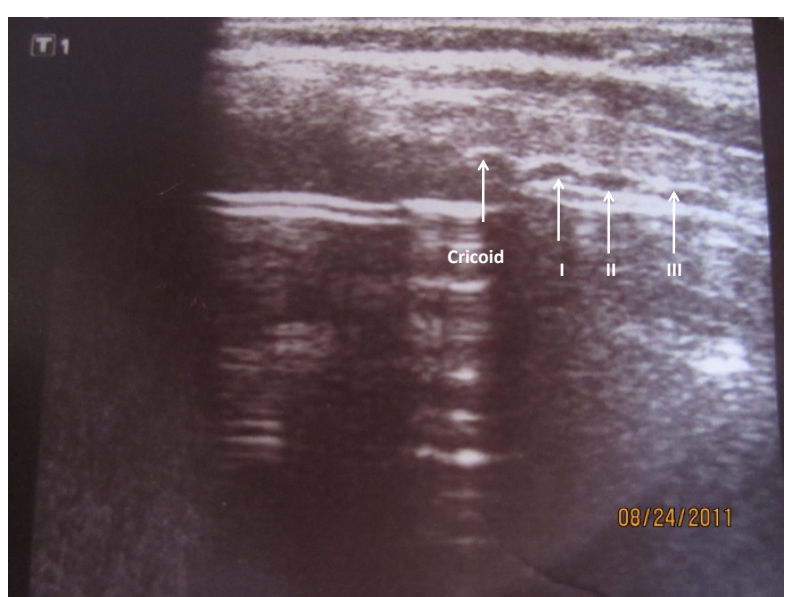

Figure 2 Ultrasound image of the trachea. Longitudinal view of the trachea shows the cricoid cartilage and the tracheal rings; important anatomical references to localize the site of puncture of the trachea. The endotracheal tube has been pulled back. I, II, III (first, second, and third tracheal rings); image obtained with an 8 $\mathrm{MHz}$ vascular probe. 


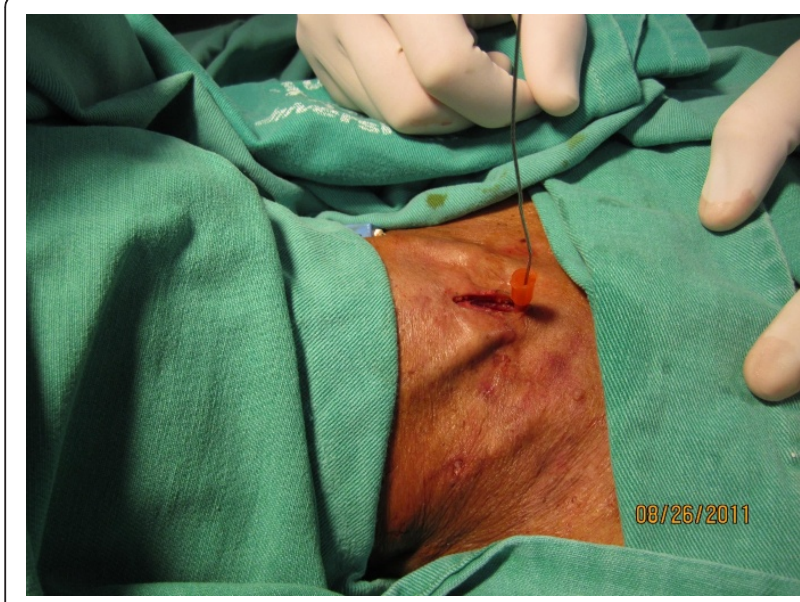

Figure 3 The guidewire in position. The guidewire is passed into the tracheal lumen through the $14 \mathrm{G}$ intravenous catheter.

tracheal orifice open (Figure 5). A flexible, spherical tip introducer $(6 \mathrm{~mm}$ internal diameter) is inserted into the airway under direct vision, facilitated by the retractor which is removed afterwards (Figure 6). A tracheostomy tube is placed inside the trachea passing over the guidewire and the flexible introducer (Figure 7). At this point the flexible introducer and the guidewire are removed, the cuff is inflated, and the patient is ventilated via the tracheostomy tube. The endotracheal tube is completely removed after adequate ventilation is confirmed by endexpiratory volume on the ventilator and auscultation of the patient. The tracheostomy cannula is secured in place with a neckband, and a chest radiograph is performed. Statistical analysis was performed using Graph Pad Prism (GraphPad Prism Software, Inc., San Diego,

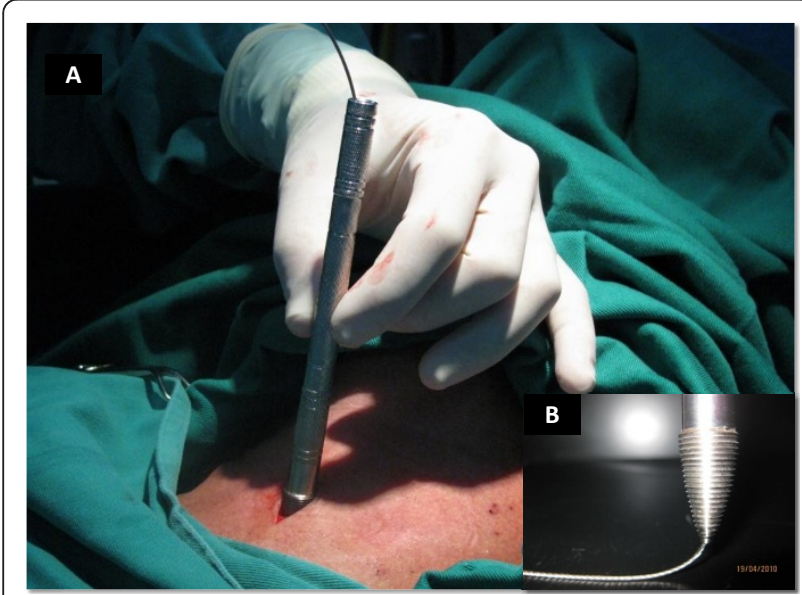

Figure 4 The threaded tip dilator. Picture (A) shows the threaded tip dilator in the incision. Insert (B) depicts how the guidewire, passing through the tip of the threaded dilator, prevents the threads from "catching" other structures.

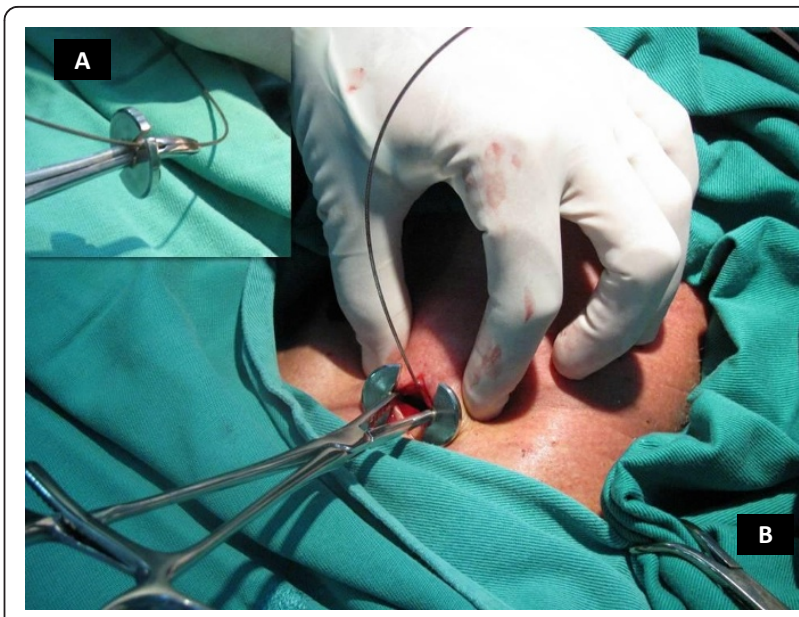

Figure $\mathbf{5}$ The self-retaining retractor. Insert (A) depicts how the self-retaining retractor is passed over the guidewire in locked position. Picture (B) shows how the retractor enables hands free lateral retraction of the pre-tracheal soft tissue, and the aperture on the anterior tracheal wall. The limiter ridge prevents insertion of the retractor too far into the trachea.

CA). Data are reported as the mean \pm SEM and percentages.

\section{Results}

During the study period, 100 patients underwent percutaneous tracheostomy by the modified technique described in this study. All percutaneous tracheostomies were performed on intubated patients at the bedside. Ninety patients $(90 \%)$ underwent the procedure in the ICU. The remaining 10 patients were in another hospital location: 4 patients were in the hospital step-down unit, 3 in the trauma room, and 3 in the post-anesthesia

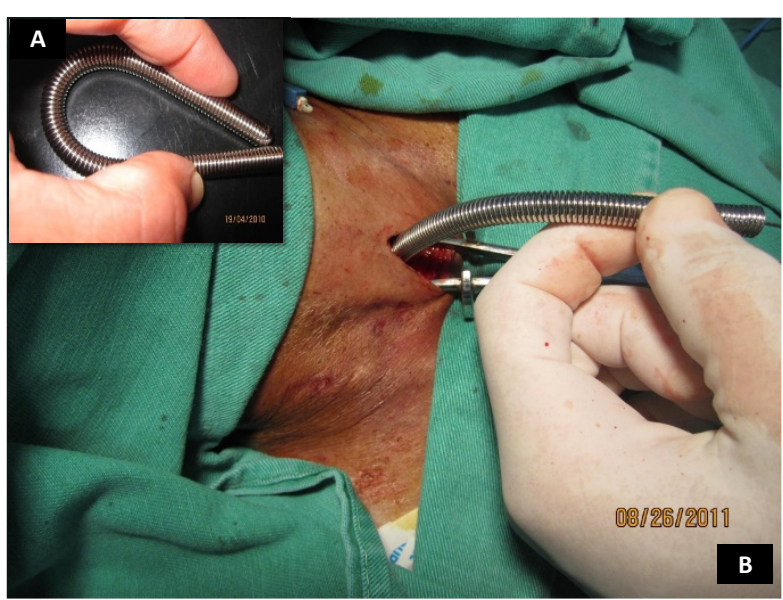

Figure 6 The spherical tip flexible introducer. Insert (A) depicts the elastic property of the introducer constructed with a circular helical spring. Picture (B) shows the flexible introducer positioned in the trachea facilitated by the self-retaining retractor. 


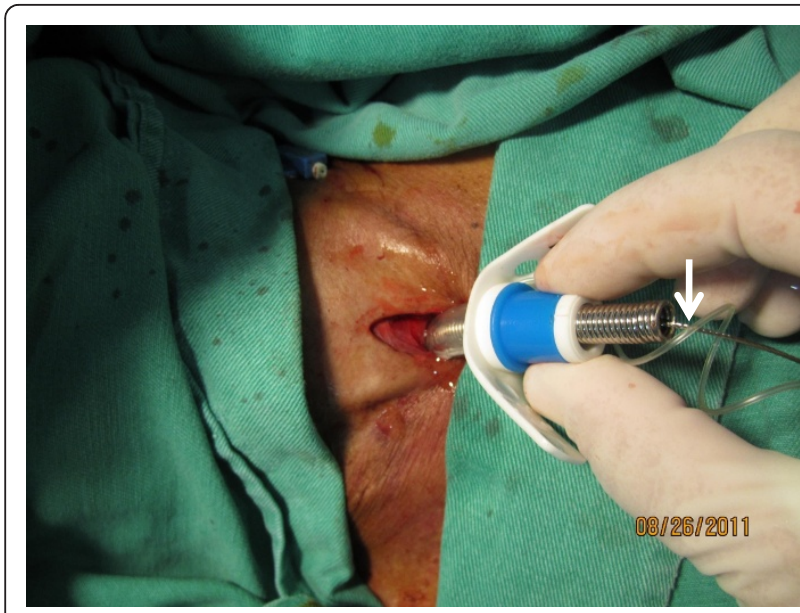

Figure 7 Insertion of the tracheostomy tube in the trachea. Picture shows the insertion of the tracheostomy tube in the trachea over the spherical tip flexible introducer. Arrow depicts the guidewire inside the introducer.

recovery room. Demographic data showed that the majority of the patients were men (68\%) with a mean age of $49 \pm 2.2$ years. The mean BMI of the patients was $25.6 \pm 2.1$, and the thyromental distance was $6.2 \pm$ $0.3 \mathrm{~cm}$. The pretracheal tissue thickness was $1.5 \pm 0.7$ $\mathrm{cm}$. Twenty five percent of the percutaneous tracheostomies were performed on trauma patients, and $18 \%$ on acute care surgery non-trauma patients. The remaining patients were admitted to the hospital because of clinical (29\%) or neurologic (28\%) related diseases. The most common indication for percutaneous tracheostomy (95 patients) was the need for prolonged ventilatory support, with a mean intubation period of $9.5 \pm 4.2$ days. Five patients underwent the procedure because of severe maxillofacial trauma. Percutaneous tracheostomy procedure time was $5.1 \pm 0.3$ minutes, assessed from the time of skin incision to the time of placement of the tracheostomy tube inside the airway. A tracheostomy tube size $9.0 \mathrm{~mm}$ (internal diameter) was used in 70 patients (70\%), a size $8.5 \mathrm{~mm}$ (internal diameter) was used in 20 patients, and a tube size $8.0 \mathrm{~mm}$ in the remaining patients.

The mean prothrombin time prior to the procedure was $80.9 \pm 5.5 \%$ (Quick Value), the activated partial thromboplastin time was $30.6 \pm 1.9$ seconds, the mean INR was $1.2 \pm 0.1$, and platelet count was $216.3 \pm 35.5$ $\mathrm{x} 10^{3} / \mathrm{uL}$.

Patients were followed for an average of $6.6 \pm 2.2$ days for complications. There were no inadvertent extubations, tracheostomy cannula misplacements and false passages, or oxygen desaturation below 95\%, in the patients of the study. Furthermore, post-procedure chest radiograph showed no pneumothorax and no subcutaneous emphysema in the neck. There were two bleeding complications (2\%) that resolved with dressing changes. Hemodialysis and anticoagulation shortly after the procedure could have contributed to the bleeding episode in one of the cases. There were no conversions to open surgical tracheostomy, and no deaths related to percutaneous tracheostomy in this study.

Bronchoscopy was performed in the first ten patients. In all cases, midline tracheal puncture, proper positioning of the thread tip dilator, as well as, integrity of the posterior wall of the tracheal were confirmed during the procedure.

\section{Discussion}

Percutaneous tracheostomy via the modified Seldinger technique was first described in 1969, and has gained several variants since then [2,5-17]. One of the main advantages of percutaneous tracheostomy is bedside performance, thus eliminating the expenses and logistics involved in operating room set-up usually required for open surgical tracheostomies. Furthermore, several investigators have reported shorter procedure times and lower complication rates with percutaneous tracheostomy compared to open surgical tracheostomy [4,11,14,15,18-22].

The percutaneous tracheostomy method described in this study combines technical principles common to other well consolidated techniques, particularly the Percu Twist ${ }^{\mathrm{TM}}$, and the Griggs-Portex ${ }^{\circledR}$ procedures; and to a lesser extent the Schachner method [2,4,5,7,10,23-25].

Our experience of 100 cases underscores three important features of the technical variation described herein. First is the capability to produce the initial breach on the trachea smoothly, with minimal compression, facilitated by the fine threads on the dilator. Additionally, the anterior tracheal wall is pulled away from the posterior wall as the dilator is threaded into the trachea, thus reducing posterior wall injury. Furthermore, passage of the guidewire through the tip of the dilator prevents the threads from "catching" the posterior wall, also reducing inadvertent injury (Figure 4).

The second feature is the capability to maintain hands-free retraction of the pre-tracheal soft tissue, and the tracheal aperture, with the self retaining retractor. The device enables controlled lateral dilation of the tracheal breach up to $2 \mathrm{~cm}$ maximum, thereby preventing excessive dilatation. Interestingly, a safety evaluation study in adult cadavers demonstrated that the mean force required to dilate the trachea 1.5 to $2 \mathrm{~cm}$ with a Griggs forceps, was two times that for therapeutic tracheal dilatation and three times the force required for tracheal disruption (31.6 N vs. $97.7 \mathrm{~N}$ ), respectively [26]. The strategic location of the limiter ridge on the retractor $(1.5 \mathrm{~cm}$ from the tip) is an additional safety feature 
to prevent insertion of the retractor too far into the trachea, and posterior wall injury.

The third feature relates to the flexible introducer which is constructed with a circular helical spring that confers elasticity, and enough rigidity to safely avoid false passage and tracheostomy tube misplacement. Tracheostomy tubes of 7 to $9.5 \mathrm{~mm}$ internal diameter can be passed over the introducer and placed inside the airway.

Even though the percutaneous tracheostomy procedure described in this study incorporates technical principles of at least two different methods the mean procedure time (5.1 minutes) was consistent with single dilator techniques reported by others $[10,13,21,27]$.

Acute complications with the percutaneous tracheostomy method described by us were restricted to hemorrhage. The post-procedure bleeding rate of $2 \%$ in our study is comparable to other reports (1.6 - 4\%) $[3-5,10,11,15,18,19,23,24]$. Even though comparison of the method described herein was not the purpose of this study, a contemporary analysis of 30 open surgical tracheostomies performed in our institution showed a $4 \%$ incidence of post-procedure bleeding, $50 \%$ of those cases required a surgical intervention to control the hemorrhage (unpublished data- Joao B. Rezende-Neto). On the contrary, none of the percutaneous tracheostomy patients who had a bleeding complication required a surgical intervention in the present study. Interestingly, prothrombin (Quick Value) time and INR were equivalent among the patients, respectively; $80.9 \pm 5.5 \%$ in percutaneous tracheostomy vs. $87.2 \pm 3.1 \%$ in open surgical tracheostomy patients $(p=0.27$, Student's $t$ Test), and $1.2 \pm 0.1$ in percutaneous tracheostomy vs. $1.3 \pm 0.15$ in open surgical tracheostomy patients $(p=$ 0.64 , Student's $t$-Test). Furthermore, time to perform time to perform percutaneous tracheostomy was significantly shorter than that of open surgical tracheostomy $(5.1 \pm 0.3$ minutes vs. $12.2 \pm 1.4$ minutes; $p<0.001$, Student's $t$-Test)

Several studies highlight the importance of bronchoscopy to reduce complications during percutaneous tracheostomies, and most institutions routinely perform the procedure under bronchoscopic guidance $[4,11,18,19,24,28-32]$. Unfortunately, our institution did not have bronchoscopy routinely available during the study period.

Even though bronchoscopy is considered an important adjunct to percutaneous tracheostomy, that enables confirmation of midline puncture of the trachea, correct position of the guidewire and the tracheostomy tube, as well as, visualization of posterior tracheal wall injury, it is not without complications $[4,31,33,34]$. Studies have shown that bronchoscopy can cause hypoventilation that leads hypercarbia and respiratory acidosis during percutaneous tracheostomy $[12,35,36]$. Nonetheless, percutaneous tracheostomy without bronchoscopic guidance remains a controversial issue [4,12,19,29,31,34,37-40].

Investigators who forgo bronchoscopy during percutaneous tracheostomy usually implement additional measures to compensate for the lack of intraluminal visualization of the trachea [12,18,37-39,41-44]. For example, dissection of the subcutaneous tissue down to the pre-tracheal fascia prior to tracheal puncture, palpation of the trachea through the incision during endotracheal tube positioning and tracheal puncture, verification of free mobility of the guidewire throughout the procedure, and capnography assessed at the puncture site [12,18,37-39,41-44]. Additionally, ultrasound has become an increasingly used adjunct to percutaneous tracheostomy when bronchoscopy is not available, particularly in obese patients. Several studies have shown that sonography is helpful to delineate the anatomy of the neck prior to the procedure; particularly the thyroid gland, pre-tracheal vascular structures, the thyroid and cricoid cartilages, and the first three tracheal rings [18,24,45-48]. Real-time ultrasound guidance makes it possible to follow the needle path during tracheal puncture, and the final position of the tracheostomy tube [46,49-51]. Because of unavailability of bronchoscopy in our institution, real time ultrasound was the main adjunct to the percutaneous tracheostomy technique described in this study.

There are several limitations to this study. There is the possibility that the low complication rate with our technique could be linked to the favorable anatomic features of our patients, defined by a mean thyromental distance $>6 \mathrm{~cm}$ and a mean BMI of 25.6. Previous studies have shown that a short thyromental distance and a high BMI are useful predictors of difficult intubation and a challenging surgical airway [52-55]. Another point is the coagulation parameters of our patients. There is the possibility that the low incidence of bleeding complications with the technique would not have been obtained if patients with abnormal coagulation parameters were included in the study. Unfortunately we did not assess the patients for other risk factors, such as, pre-procedure positive end expiratory pressure $>10 \mathrm{~cm}$ $\mathrm{H}_{2} \mathrm{O}$ or fraction of inspired oxygen $>50 \%$ [4]. Even though, the follow-up period in the study was sufficiently long for the determination of acute complications, it did not extend long enough for detection of long term complications, such as post-procedure tracheal stricture, associated with our method. That limitation is corroborated by previous reports that show late symptoms related to percutaneous tracheostomies in up to $20 \%$ of the patients followed for 39 months 
$[4,20,46,56]$. Furthermore, only 10 patients in our study underwent bronchoscopic guided percutaneous tracheostomy, thus significantly limiting our capability to determine complications and the shortcomings of the technique. Even though the technique can be performed without bronchoscopic guidance, it should be used whenever available, particularly during the learning curve which is of approximately 20 patients for percutaneous dilatational tracheostomy [57]. Lastly, we did not compare our method to other percutaneous tracheostomy techniques; unfortunately, we do not have commercial tracheostomy kits readily available at our institution. Nonetheless, our results were in accordance with the data from other publications.

\section{Conclusions}

In our experience, percutaneous tracheostomy performed with the technical modification described in this study, is safe and simple to execute. However, long term follow-up for complications, is warranted. Additionally, reproducibility of results and a comparison to commercially available tracheostomy kits are required to further validate the method.

\section{Abbreviations}

ICU: Intensive Care Unit; BMI: Body Mass Index; and INR: International Normalized Ratio.

\section{Acknowledgements}

We thank Coordenacao de Aperfeicoamento de Pessoal de Nivel Superior (CAPES) - Brazil, and Fundacao de Amparo a Pesquisa do Estado de Minas Gerais - Brazil, for support in the decision to submit the manuscript for publication. We thank Emanuelle Savio - Trauma Case Manager, and the Respiratory Therapists of the Risoleta Tolentino Neves Hospital for their support.

\section{Author details}

${ }^{1}$ Universidade Federal de Minas Gerais and Risoleta Tolentino Neves Hospital, Brazil. ${ }^{2}$ Risoleta Tolentino Neves Hospital, Brazil. ${ }^{3}$ University of Toronto and Sunnybrook Hospital, Canada.

\section{Authors' contributions}

Conception of the technique, design of the study, acquisition and interpretation of data, and drafting of the manuscript (JBRN); acquisition and interpretation of data, and execution of bedside ultra-sound (AJO); acquisition and interpretation of data, and drafting of the manuscript (MPN); interpretation of data and drafting of the manuscript (FAB); drafting of the manuscript and revision for important intellectual content (SBR). All authors read and approved the final manuscript.

\section{Authors' information}

JBRN - Associate Professor Department of Surgery Universidade Federal de Minas Gerais, Brazil. Chief of Trauma and Acute Care Surgery Risoleta Tolentino Neves Hospital.

AJO - Intensivist Risoleta Tolentino Neves Hospital

MPN - Trauma Surgeon Risoleta Tolentino Neves Hospital.

FAB - Assistant Professor of Internal Medicine Universidade Federal de Minas Gerais, Brazil. Chief of Critical Care Medicine Risoleta Tolentino Neves Hospital.

SBR - Associate Professor of Surgery and Critical Care Medicine University of Toronto and Sunnybrook Hospital, De Souza Trauma Research Chair.

\section{Competing interests}

The Universidade Federal de Minas Gerais (Dr. Joao B. Rezende-Neto) filed a patent application for the technique and the device described in this manuscript (Patent Pending Number 902833073 - INPI - Brazil). All other authors declare that they have no competing interests in relation to this manuscript.

Received: 30 August 2011 Accepted: 2 November 2011

Published: 2 November 2011

\section{References}

1. Yu M: Tracheostomy patients on the ward: multiple benefits from a multidisciplinary team. Critical Care 2010, 14:109.

2. Ciaglia P, Firsching R, Syniec C: Elective percutaneous dilational tracheostomy: a new simple bedside procedure; preliminary report. Chest 1985, 87:715-719.

3. Petros S: Percutaneous tracheostomy. Crit Care 1999, 3:R5-R10.

4. Kornblith LZ, Burlew CC, Moore EE, Haenel JB, Kashuk JL, Biffl WL, Barnett CC, Johnson JL: One thousand bedside percutaneous tracheostomies in the surgical intensive care unit: time to change the gold standard. J Am Coll Surg 2011, 2:163-170.

5. Griggs WM, Worthley LIG, Gilligan JE, Thomas PD, Myburg JA: A simple percutaneous tracheostomy technique. Surg Gynec Obstet 1990, 170:543-545

6. Fantoni A, Ripamonti D: A non-derivative, non-surgical tracheostomy: the trans-laryngeal method. Intensive Care Med 1997, 23:386-389.

7. Schachner A, Ovil Y, Sidi J, Rogev M, Heilbronn Y, Levy MJ: Percutaneous tracheostomy - A new method. Crit Care Med 1989, 17:1052-1089.

8. Sheldon $\mathrm{CH}$, Pudenz RH, Freshwater DB, Cure BL: A new method for tracheostomy. J Neurosurg 1995, 12:428-431.

9. Toy FJ, Weinstein JD: A percutaneous tracheostomy device. Surgery 1969, 65:384-389.

10. Westphal K, Maeser D, Scheifler G, Lischke V, Byhahn C: PercuTwist: A new single-dilator technique for percutaneous tracheostomy. Anesth Analg 2003, 96:229-232.

11. Fernandez L, Norwood S, Roettger R, Gass D, Wilkins H: Bedside percutaneous tracheostomy with bronchoscopic guidance in critically ill patients. Arch Surg 1996, 131:129-132.

12. Paran H, Butnaru G, Hass I, Afanasyv A, Gutman M: Evaluation of a modified percutaneous tracheostomy technique without bronchoscopic guidance. Chest 2004, 126:868-871.

13. Sengupta $N$, Ang KL, Prakash D, George SJ: Twenty months' routine use of a new percutaneous tracheostomy set using controlled rotation dilation. Anesth Analg 2004, 99:188-192.

14. Toye FJ, Weinstein JD: Clinical experience with percutaneous tracheostomy and cricothyroidotomy in 100 trauma patients. J Trauma 1986, 26:1130-1140.

15. Bove MJ, Afifi MS: Tracheotomy procedure. In Tracheostomies: the complete guide. Edited by: Morris L, Afifi S. New York: Springer Publishing Company; 2010:17-40.

16. Toye FJ, Weinstein JD: A percutaneous tracheostomy device. Surgery 1969, 65:384-389.

17. Ernest LW, Brink PRG: The history of percutaneous tracheostomy. J Laryngol Otol 1996, 110:723-726.

18. Marx WH, Ciaglia P, Graniero KD: Some important details in the technique of percutaneous dilatational tracheostomy via the modified Seldinger technique. Chest 1996, 110:762-766.

19. Marelli D, Paul A, Manolidis S, Walsh G, Odim JN, Burdon TA, Shennib H, Vestweber KH, Fleiszer DM, Mulder DS: Endoscopic guided percutaneous tracheostomy: early results and consecutive trial. J Trauma 1990, 30:433-435.

20. van Heurn LW, Goei R, Ploeg I, Ramsay G, Brink PR: Late complications of percutaneous dilatational tracheostomy. Chest 1996, 110:1572-1576.

21. Kost KM: Percutaneous tracheostomy: comparison of Ciaglia and Griggs techniques. Crit Care 2000, 4:143-146.

22. Delaney A, Bagshaw SM, Nalos M: Percutaneous dilatational tracheostomy surgical tracheostomy in critically ill patients: a systematic review and meta-analysis. Crit Care 2006, 10:R55.

23. Friedman Y, Mayer AD: Bedside percutaneous tracheostomies in critically ill patients. Chest 1993, 104:532-535. 
24. Hill BB, Zweng TN, Maley RH, Charash WE, Tourasarkissian B, Kearney PA Percutaneous dilational tracheostomy: report of 356 cases. J Trauma 1996, 40:238-243.

25. Brambrink A: Percutaneous dilatation tracheostomy: which technique is the best for the critically ill patient, and how can we gather further scientific evidence? Crit Care 2004, 8:319-321.

26. Watters M, Thorne G, Cox C, Monk C: Tracheal trauma from percutaneous tracheostomy using the Griggs method. Anaesthesia 2002, 57:249-252.

27. Montcriol A, Bordes J, Asencio Y, Prunet B, Lacroix G, Meaudre E: Bedside percutaenous tracheostomy: a prospective randomised comparison of PercuTwist versus Griggs' forceps dilational tracheostomy. Anaesth Intensive Care 2011, 39:209-216.

28. Sarkar S, Kelly A, Townsend R: Survey of percutaneous tracheostomy practice in UK intensive care units. JICS 2009, 10:138-140.

29. Hinerman R, Alvarez F, Keller CA: Outcome of bedside percutaneous tracheostomy with bronchoscopic guidance. Intensive Care Med 2000, 26:1850-1856.

30. Kluge S, Baumann HJ, Maier C, Klose H, Meyer A, Nierhaus A, Kreymann G: Tracheostomy in the intensive care unit: $\mathrm{A}$ nationwide survey. Anesth Analg 2008, 107:1639-1643.

31. Barba CA, Angood PB, Kauder DR, Latenser B, Martin K, McGonigal MD, Phillips GR, Rotondo MF, Schwab W: Bronchoscopic guidance makes percutaneous tracheostomy a safe, cost-effective, and easy-to-teach procedure. Surgery 1995, 118:879-883

32. Fikkers $B G$, van Veen JA, Kooloos JG, Pickkers $P$, van den Hoogan FJA, Hillen B, van der Hoeven JG: Emphysema and pneumothorax after percutaneous tracheostomy: Case reports and an anatomic study. Chest 2004, 125:1805-1814.

33. Trottier SJ, Hazard PB, Sakabu SA, Levine JH, Troop BR, Thompson JA McNary R: Posterior tracheal wall perforation during percutaneous dilatational tracheostomy: An investigation into its mechanism and prevention. Chest 1999, 115:1383-1389.

34. Reilly PM, Shapiro MB, Malcynski JT: Percutaneous dilatational tracheostomy under the microscope: justification for intra-procedural bronchoscopy? Intensive Care Med 1999, 25:3-4.

35. Reilly PM, Anderson HL III, Sing RF, Schwab W, Bartlett RH: Occult hypercarbia: An unrecognized phenomenon during percutaneous endoscopic tracheostomy. Chest 1995, 107:760-763.

36. Reilly PM, Sing RF, Giberson FA, Anderson HL III, Rotondo MF, Tinkoff GH, Schwab CW: Hypercarbia during tracheostomy: a comparison of percutaneous endoscopic, percutaneous Doppler, and standard surgical tracheostomy. Intensive Care Med 1997, 23:858-864.

37. Ahmed R, Rady SR, Siddique JIM, labal M: Percutaneous tracheostomy in critically ill patients: 24 months experience at a tertiary care hospital in the United Arab Emirates. Ann Thorac Med 2010, 5:26-29.

38. Veenith T, Ganeshamoorthy S, Standley T, Carter J, Young P: Intensive care unit tracheostomy: a snapshot of UK practice. Int Arch Med 2008, 1:21-27.

39. Park SS, Goldenberg D: Percutaneous tracheostomy: Griggs technique. Operative Techniques in Otolaryngology 2007, 18:95-98.

40. Grundling M, Pavlovic D, Kuhn SO, Feyerherd F: Is the method of modified percutaneous tracheostomy without bronchoscopic guidance really simple and safe? Chest 2005, 128:3774-3775.

41. Dawood AA, Haddad S, Arabi Y, Dabbagh O, Cook DJ: The safety of percutaneous tracheostomy in patients with coagulopathy of thrombocytopenia. MEJ Anesth 2007, 19:37-50.

42. Maddalli M, Pratap M, Fahr J, Zarroug AW: Percutaneous tracheostomy by guidewire dilating forceps technique: is bronchoscopic guidance mandatory? Middle East J Anesthesiol 2002, 16:509-519.

43. Mallick A, Venkatanath D, Elliot SC, Hollins T, Kumar CGN: A prospective randomised controlled trail of capnography vs. bronchoscopy for Blue Rhino $^{\text {TM }}$ percutaneous tracheostomy. Anaesthesia 2003, 58:864-868.

44. Atweh NA, Possenti PP, Caushaj PF, Burns G, Pineau MJ, Ivy M: Dilatational percutaneous tracheostomy: Modification of technique. J Trauma 1999, 47:142-144.

45. Sustic A, Kovac D, Zgaljardic Z, Zupan Z, Krstulovic B: Ultrasound-guided percutaneous dilatational tracheostomy: A safe method to avoid cranial misplacement of the tracheostomy tube. Intensive Care Med 2000, 26:1379-1381.

46. Kollig E, Heydenreich U, Roetman B, Hopf F, Muhr G: Ultrasound and bronchoscopic controlled percutaneous tracheostomy on trauma ICU. Injury 2000, 31:663-668
47. Hatfield A, Bodenham A: Portable ultrasound scanning of the anterior neck before percutaneous dilatational tracheostomy. Anesthesia 1999, 54:660-663.

48. Brueggeney MK, Greif R, Ross S, Eichenberger U, Moriggl B, Arnold A, Luyet C: Ultrasound-guided percutaneous tracheal puncture: $\mathrm{A}$ computer-tomographic controlled study in cadavers. Br J Anaesth 2011, 106:738-742.

49. Rajajee $V$, Fletcher JJ, Rochlen LR, Jacobs TL: Real-time ultrasound-guided dilatational percutaneous tracheostomy: a feasibility study. Crit Care 2011, 15:R67.

50. Sustic A: Role of ultrasound in the airway management of critically ill patients. Crit Care Med 2007, 35(Suppl 5):137-177.

51. Szeto C, Kost K, Hanley JA, Roy A, Christou N: A simple method to predict pretracheal tissue thickness to prevent accidental decannulation in the obese. Otolaryngol Head Neck Surg 2010, 143:223-229.

52. Baker PA, Depuydt A, Thompson JM: Thyromental distance measurement: Fingers don't rule. Anaesthesia 2009, 64:878-882.

53. Aldawood AS, Arabi YM, Haddad S: Safety of percutaneous tracheostomy in obese critically ill patients: A prospective cohort study. Anaesth Intensive Care 2008, 36:69-73.

54. Kim WH, Ahn HJ, Lee CJ, Shin BS, Ko JS, Choi SJ, Ryu SA: Neck circumference to thyromental distance ratio: A new predictor of difficult intubation in obese patients. Br J Anaesth 2011, 106:743-748.

55. Connor CW, Segal S: Accurate classification of difficult intubation by computerized facial analysis. Anesth Analg 2011, 112:84-93.

56. Rosenbower TJ, Morris JA Jr, Eddy VA, Ries WR: The long term complications of percutaneous dilatational tracheostomy. Am Surg 1998, 64:82-86.

57. Massick DD, Powell DM, Price PD, Chang SL, Squires G, Forrest LA Young DC: Quantification of the learning curve for percutaneous dilatational tracheostomy. Laryngoscope 2000, 110:222-228.

doi:10.1186/1749-7922-6-35

Cite this article as: Rezende-Neto et al:: A technical modification for percutaneous tracheostomy: prospective case series study on one hundred patients. World Journal of Emergency Surgery 2011 6:35.

\section{Submit your next manuscript to BioMed Central and take full advantage of:}

- Convenient online submission

- Thorough peer review

- No space constraints or color figure charges

- Immediate publication on acceptance

- Inclusion in PubMed, CAS, Scopus and Google Scholar

- Research which is freely available for redistribution 